\author{
Черняк Г.А. \\ кандидат исторических наук, доцент \\ e -mail: morreg@ukr.net \\ Ангелов Г.В. \\ доктор философиии, профрессор \\ кафедра социологии, фрилософии и права \\ Одесская национальная академия пищевых технологий \\ ул. Канатная, 112, г. Одесса, Украина, 65039 \\ E-mail: sociologia.kafedra@mail.ru
}

\title{
ПСИХОЛОГИЧЕСКИЕ АСПЕКТЫ МЕНЕДЖЕРСКОГО ПОТЕНЦИАЛА СТУДЕНТОВ ТЕХНИЧЕСКОГО ВУЗА
}

В статье рассматривается актуальная роль психолого-педагогических знаний, в модернизируемом образовательном процессе высшей школы, при формировании менеджерского потенциала будущих специалистов. Описаны подходы гармонизирующие межличностные отношения, снижающие показатели, которые характеризуют агрессивность, не сдержанность, обидчивость, неприятие друг друга и т.д.

Ключевые слова: менеджерский потенциал; психологические и педагогические знания; студенты вузов; межличностное общение; гармонизация межличностных отношений; поведенческая регуляция; коммуникативный потенциал; уровень морально-нравственной нормативности; личностноадаптационный потенциал; стратегия поведения и социализация.

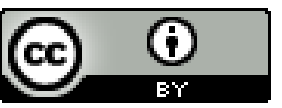

This work is licensed under a Creative Commons Attribution 4.0 International License http://creativecommons.org/licenses/by/4.0/
Постановка проблемы и ее связь с важными научными и практическими заданиями. Для формирования менеджерского потенциала студентов технического вуза полезно отказаться от укоренившегося представления о том, что психология, указывая на человека, отвлекает руководителя от его непосредственного дела, якобы призывая заниматься воспитанием, морализированием, перестать быть требовательным и строгим менеджером. Психология управления не побуждает менеджера играть роль педагога, изменять свою управленческую идеологию. Она исходит из того, что в теории и практике управления есть обширное «белое пятно» - область проблем, которые не только не находят разрешения, но нередко даже не осознаются, вызывая тем не менее стресс, общее беспокойство. Это белое пятно - результат того, что не учитывается двухслойная структура управленческой деятельности. Ее суть проста: перед менеджером любого ранга, если в его подчинении есть хотя бы один человек, всегда стоят две группы задач. Первая - задачи, связанные с организацией деятельности своего подразделения, взаимодействия с другими подразделениями и вышестоящим руководством. Вторая - внутренние проблемы подразделения, входящих в его состав людей. Это вопросы трудовой морали, или мотивации деятельности, дисциплины, корпоративной культуры, климата, взаимоотношений, работоспособности, личностного и группового развития людей, авторите- та самого менеджера и органа управления.

Решение менеджера эффективно, если оно психологически обосновано, исходит из адекватной оценки морально-психологической обстановки в коллективе и прогноза ее динамики. Психологически грамотные распоряжения и другие управленческие действия имеют два признака:

- они учитывают уровень внутренней готовности сотрудников к намечаемым переменам;

- содержат в себе средства, повышающие в случае необходимости готовность исполнителей делать то, что предусматривается замыслом руководителя.

Никто не сделает этого лучше самого руководителя. Но нужны соответствующие умения и мотивы, формирование которых входит в программу базовой психологической подготовки студентов Одесской национальной академии пищевых технологий при формировании их менеджерского потенциала.

Анализ последних публикаций по проблеме. В процессе исследования учеными кафедры социологии, философии и права Одесской национальной академии пищевых технологий были поставлены и в определенной степени решены следующие задачи:

теоретические положения влияния психологических знаний на формирование менеджерского потенциала студентов технических вузов изложены в работах Г.А.Черняк [4], 
В.В.Левчука,

А.В.Мишковец,

С.В.Котлика, В.И.Калашника, И.Н.Агеевой, Ю.Г.Неустроева, Г.В.Ангелова [3], В.В.Стремядина, И.Н.Буценко, В.В.Паламарчука; -теоретические

положения профессионального потенциала менеджера, как целостной самоуправляемой и саморазвивающейся системы, которая включает в себя ресурсные менеджерские возможности студентов на общем уровне специального профессионального образования (К.М.Тенюх. О.О.Стояно, Д.М Демченко, С.З.Трошев, Г.В. Ангелов [9], А.И.Киссе); -теоретические положения структуры менеджерского потенциала (Г.В.Ангелов, В.А.Семов, В.М.Чугуенко) [8]; -теоретико-эмпирические особенностей формирования потенциала студентов технических вузов (Г.А.Черняк, Г.В.Ангелов, А.П.Заричанский, А.Ф.Кропивко, В.И.Мазуренко) [5];

- подготовки студентов высших учебных технических заведений к менеджерской деятельности (Г.А.Черняк, И.А. Гордиенко, И.Н. Буценко, О.В.Дышкантюк, С.М.Тодорова, О.А.Титлова, А.А. Шевченко, Т.Е.Шарахматова, А.В.Черкасский, Г.В. Ангелов) [7], (Г.А.Черняк, И.Н.Буценко, Л.Ф.Коваленко, В.В.Паламарчук, С.3.Трошев, Г.В.Ангелов) [6];

- теоретические положения психологических особенностей деятельности менеджеров (С.Е.Шувалов, О.В.Романенко, Г.В.Ангелов) [10].

Таким образом, разные аспекты формирования менеджерского потенциала студентов технического вуза стали предметом рассмотрения многими учеными кафедры в рамках работы над кафедральной целевой комплексной программой «Социально-философские, политико-правовые и социолого-психологические проблемы освоения инновационных технологий в социальном управлении и коммуникациях».

Формирование целей исследования. Целью исследования является проведение анализа основных механизмов формирования менеджерского потенциала будущих специалистов, раскрыть сущность профессионализма и личностные особенности успешного менеджера, представить новейшие технологии профессионального роста и обозначить особенности их использования в деятельности менеджера, представить достоинства и недостатки командно-административного управления, с тем, чтобы оттенить преимущества современного коучинга как системы личностного и командного роста и успеха, а так же осветить основные вопросы психологии общения в деятельности менеджера и раскрыть основные приемы скрытого управления в деятельности менеджера.

Изложение основных результатов и их обоснование. Как известно, успешный рост и развитие любой организации требует целенаправленного формирования профессионально- го потенциала сотрудников. Это наиболее актуально по отношению к управленческим кадрам. С нашей точки зрения под профессиональным потенциалом менеджера следует понимать целостную самоуправляемую и саморазвивающуюся систему, включающую в себя ресурсные возможности менеджера. Последние основаны на общем уровне специального психолого-педагогического профессионального образования, включении его в управленческую деятельность и состоят из следующих компонентов: личностных качеств, профессионально-управленческих знаний и способностей в сфере управленческой деятельности. Поэтому современная система высшего технического образования направлена на формирование профессионального класса менеджеров, обладающих профессионально-важными качествами.

Психологическую

структуру профессионально-важных качеств менеджера образуют различные компоненты четырех блоков качеств. К первому блоку относятся качества, определяющие профессиональную направленность руководителя. В этот блок входят общий показатель осмысленности жизни, мотивация достижения, компетентность во времени (целостное видение своей жизни) и поддержка (степень независимости ценностей субъекта от воздействия извне). Второй блок наполняют мыслительные качества, к которым мы относим системность, динамичность, нестандартность, креативность мышления и общий уровень интеллектуального развития. Третий блок включает организаторские качества: ориентация на конкретный результат деятельности, умение планировать и проектировать, руководство группой. Четвертый блок образован коммуникативными качествами: эффективность взаимодействия с людьми, гибкость в общении и способность к ведению переговоров. Анализ исследований в области менеджмента позволяет выделить пять групп качеств, которыми должен обладать современный руководитель:

1) общечеловеческие качества: трудолюбие, принципиальность, обязательность, самокритичность, человечность, корректность, справедливость, целеустремленность, высокая общая культура, безупречная нравственность, предприимчивость, хладнокровие, любовь к своему делу, оптимистичность, требовательность к себе и другим, чувство юмора, внешняя привлекательность и многие другие;

2) психофизиологические качества: крепкое здоровье, высокая трудоспособность, устойчивость к стрессам, должный общий уровень развития, интеллектуальные свойства и индивидуальнотипологические особенности личности;

3) деловые качества и организаторские способности: инициативность, самостоятельность в решении вопросов, дисциплинированность, исполнительность, умение определять цели, ставить задачи, организовать взаимодействие кадров, способность менять стиль поведения, мобилизовать 
коллектив и повести его за собой, умение контролировать деятельность подчиненных, способность оперативно принимать решения, объективно анализировать результаты, умение стимулировать подчиненных; творческий подход к исполнению порученного дела; умение поддерживать инициативу, стремление использовать все новое, прогрессивное; умение поддерживать свой авторитет;

4) коммуникативные качества: умение устанавливать деловые отношения с выше- и нижестоящими и руководителями, с подчиненными, поддерживать нормальный психологический климат в коллективе, общаться, умение выступать публично;

5) профессиональные качества: знание науки об управлении (основ менеджмента, управления персоналом и др.); применение на практике современных организационно-управленческих принципов и методов; умение работать с документацией.

Таким образом, весьма широкий круг важных качеств, определяющих менеджерский потенциал, должен быть в основном сформирован к моменту окончания вуза и являться фундаментом для дальнейшего профессионального роста руководителя. Следует отметить, что обучение в вузе характеризуется значительным эмоциональным и интеллектуальным напряжением, наличием стрессовых ситуаций, негативно влияющих на психофизиологическое состояние студентов. Экзаменационный стресс, которым завершается каждый семестр, оказывает выраженное влияние на организм студентов, вызывая повышение уровня субъективной тревоги и объективные изменения в нервной и сердечнососудистой системах. Психологическими механизмами коррекции состояния тревожности являются мотивационный и рефлексивный механизмы, способствующие формированию адекватного восприятия человеком ситуации. Психологическая коррекция формирующегося менеджерского потенциала студентов вуза может быть реализована с использованием психологических тренингов, сеансов психологической регуляции, направленных на раскрытие ресурсных возможностей и творческого потенциала. Она позволяет не только усвоить знания и сформировать полезные для жизни и профессиональной деятельности навыки, но и обеспечить соответствующее развитие и совершенствование студентов. Кроме учебных курсов по психологии студентам Одесской национальной академии пищевых технологий оказывают психологическую помощь и психологическим приемам на занятиях в институте культуры, психолого-педагогического семинара и в Центре психологической поддержки.

Результаты эмпирического исследования, в котором принимали участие 68 студентов ОНАПТ обучающихся по специальностям «менеджмент туризма», «менеджмент ресторанного и отельного бизнеса» показали, что «четкость ценностей», «саморазвитие», «творческий подход», «влиятель- ность», «понимание управления» и «умение обучаться» после проведения курса психологии достоверно не изменились, что можно интерпретировать, как отсутствие у данных групп студентов навыков и качеств, ограничивающих способности к управлению. Однако возросли такие показатели, как показатель «самоуправление», «четкость целей», «способность руководить». Таким образом факторы, сдерживающие потенциал и результаты работы организации в целом, рабочей группы или отдельного менеджера, у обследованных нами студентов, обучающихся по специальностям «менеджмент туризма», «менеджмент ресторанного и отельного бизнеса», не выявлены. Можно считать, что изучение, осознание и преодоление ограничений, препятствующих успеху и личному росту, будет являться быстрейшим и наиболее практичным способом ускорения саморазвития будущих менеджеров. Концепция ограничений личностного потенциала дает менеджеру отчетливый и исчерпывающий способ проверки имеющихся у него способностей и поиска действительных путей развития личностных и деловых качеств.

Полученные результаты свидетельствуют о том, что в настоящее время наиболее значимыми факторами для руководителя становятся не столько профессиональные знания, сколько некоторые личностные характеристики, связанные с результативными коммуникациями, взаимодействием с людьми, мотивацией на успех, созданием команд и умением работать в них, искусством ведения переговоров и достижения договоренностей. Позитивная динамика показателей, характеризующих менеджерский потенциал, под влиянием курса психологических знаний указывает на наличие возможностей его целенаправленного формирования в процессе подготовки и в вузе. В ходе социологического исследования были изучены показатели «самоуправление», «четкость целей» и «способность руководить» под влиянием психологической коррекции у студентов. Исходные показатели «хроническое утомление» и «физиологический дискомфорт» соответствуют средним популяционным значениям. После чтения курса по психологии и определенной психологической коррекции они снизились. Применение практических знаний в области психологии позволило студентам свободнее преодолевать эмоциональные и интеллектуальные напряжения, возникающие в процессе обучения вузе. Результаты исследований показали, что в исходном состоянии все индикаторы дисгармоничности отношений: «напряженность», «отчужденность», «конфликтность», «дисгармония» и «агрессивность» у данного контингента обследованных студентов находится на высоком уровне (в диапазоне от 6,75 до 7,50 стэна). Под влиянием знаний практического курса по психологии отмечается достоверное снижение по показателям «напряженность», «агрессивность» и «дисгармония». Гармония межличностных отношений характеризуется 
стройностью (упорядоченностью развития, согласованностью, слаженностью действий); равенством субъектов отношений, их позиций; взаимозависимостью субъектов отношений (обоюдной потребностью в продолжении отношений); взаимностью (общностью чувств по отношению друг к другу), единством (неразрывностью).

Выводы и перспективы дальнейших исследований. Исходя из анализа литературы и полученных социологических результатов, можно отметить, что в настоящее время наиболее значимыми факторами для руководителя становятся некоторые личностные характеристики, связанные с эффективными коммуникациями, взаимодействием с людьми, мотивацией на успех, созданием команд и умением работать в них, искусством ведения переговоров и достижения договоренностей. Отмеченная нами положительная динамика параметров менеджерского потенциала после изучения курса по психологии указывает на существование возможностей его целенаправленного формирования в процессе подготовки в вузе.

Таким образом, влияние психологических знаний на формирование менеджерского потенциала студентов технического вуза убедительно продемонстрировало положительное воздействие на такие показатели, как «навыки решения проблем», «организация работы группы», «самоуправление», «четкость целей» и «способность руководить». Также позитивное влияние курса по психологии сказалось на гармонизации межличностных отношений в исследуемых студенческих группах.

\title{
Література
}

1. Киссе А.И. Национальные особенности в современном менеджменте / Киссе А.И., Демченко Д.М., Ангелов Г.В. - Киев-Одеса: СМИЛ, 2004. - 388c.

2. Человековедческая компетентность в современном управлении / В.В.Стремядин, И.Н.Буценко, В.В.Поламарчук, Г.В.Ангелов. - Киев- Одесса: СМИЛ, 2004. - 308 с.

3. Менеджмент: инновационно-стратегические и психолого-этические аспекты: [научно-учеб. пособие] / [В.В.Левчук, А.В.Мишковец, С.В.Котлик и др.]. - Одесса: Астропринт, 2009. - 390 с.

4. Черняк Г.А. Роль психологических знаний в формировании управленческих навыков у студентов технического вуза / Черняк Г.А. // 57 научн. конф. профессорско-преподавательского состава ОГАПТ : тезисы докл. - Одесса: ОГАПТ, 1997. - С.21

5. Психология человеческих взаимосвязей: [учеб. пособие] / [Г.А.Черняк, Г.В.Ангелов, А.П.Заричанский и др.]. - Одесса: ВМВ, 1999. - 280 с.

6. Искусство эффективного общения: [учеб. пособие] / [Г.А.Черняк, И.Н.Буценко, Л.Ф.Коваленко и др.]. - Одесса: КП ОГТ, 2008. - 400 с.

7. Поиск гармонии в человеческом взаимопонимании / [Г.А.Черняк, И.А Гордиенко, И.Н Буценко и др.]. - Херсон: изд. Гринь Д.С., 2014. - 688 с.

8. Ангелов Г.В. Психолого-педагогические основы управления производством / Г.В.Агелов, В.А.Семов, В.М.Чугуенко. - Киев-Одесса: СМИЛ, 1994. - 210 с.

9. Самовизначення особистості студента як майбутнього фахівця / [К.М.Тенюк. О.О.Стояно, Д.М.Демченко та ін.]. - Київ-Одеса: СМІЛ, 2006. - 202 с.

10. Шувалов С.Е. Социолого-психологические резервы менеджмента: новые подходы / Шувалов С.Е., Романенко О.В., Ангелов Г.В. - Киев-Одесса: СМИЛ, 1997. - 280 с.

\author{
Черняк Г.А. \\ кандидат історичних наук, доцент \\ E-mail:morreg@ukr.net \\ Ангелов Г.В. \\ доктор філософії, профресор \\ кафредра соціології, фрілософрії і права \\ E-mail: sociologia.kafedra@mail.ru \\ Одеська національна академія харчових технологій \\ вул. Канатна, 112, м. Одеса, Україна, 65039
}

\section{ПСИХОЛОГІЧНІ АСПЕКТИ МЕНЕДЖЕРСЬКОГО ПОТЕНЦІАЛУ СТУДЕНТІВ ТЕХНІЧНОГО ВНЗ}

У статті розглядається актуальна роль психолого-педагогічних знань, в модернізованому освітньому процесі вищої школи, при формуванні менеджерського потенціалу майбутніх фрахівців. 
Описано підходи, які гармонізують міжособистісні відносини, що знижують показники, які характеризують агресивність, не стриманість, образливість, неприйняття один одного і т.п. Відзначено, що для формування менеджерського потенціалу студентів технічного вузу корисно відмовитися від укоріненого уявлення про те, що психологія, вказуючи на людину, відволікає керівника від його безпосереднього відношення, закликаючи займатися чи вихованням, то чи моралізування, то чи взагалі перестати бути вимогливим і суворим менеджером. Психологія керування не спонукає менеджера грати роль педагога, змінювати свою управлінську ідеологію. Вона виходить з того, що в теорії і практиці управління є велике «біла пляма» - область проблем, які не тільки не знаходять дозволу, але нерідко навіть не усвідомлюються, викликаючи тим не менше стрес, загальне занепокоєння. Це біла пляма - результат того, що не враховується двошаровий структура управлінської діяльності. Ії̈ суть проста: перед менеджером будь-якого рангу, якщо в його підпорядкуванні $€$ хоча б одна людина, завжди стоять дві групи завдань. Перша - завдання, пов'язані з організацією діяльності свого підрозділу, взаємодії з іншими підрозділами і вищим керівництвом. Друга - внутрішні проблеми підрозділи, що входять до його складу людей. Це питання трудової моралі, або мотивації діяльності, дисципліни, корпоративної культури, клімату, взаємовідносин, працездатності, особистісного та групового розвитку людей, авторитету самого менеджера і органу управління.

Ключові слова: менеджерський потенціал; психологічні та педагогічні знання; студенти вузів; міжособистісне спілкування; гармонізація міжособистісних відносин; поведінкова регуляція; комунікативний потенціал; рівень морально-етичної нормативності; особисто-адаптаційний потенціал; стратегія поведінки і соціалізація.

\section{Cherniak G. \\ PhD, Associate Professor \\ E-mail: morreg@ukr.net}

Angelov G.

Doctor of Philosophy, Professor

Department of the Sociology, Philosophy and Law

Odessa National Academy of Food Technologies

Kanatna Str., 112, Odessa, Ukraine, 65039

E-mail: sociologia.kafedra@mail.ru

\section{PSYCHOLOGICAL ASPECTS OF THE MANAGERIAL CAPACITY OF TECHNICAL COLLEGE STUDENTS}

The article discusses the current role of the psycho-pedagogical knowledge, with a modernized educational process of higher education, in the formation of managerial capacities of future specialists.

The approaches that harmonize interpersonal relationships, reduce performance, characterized by an aggressive, not restraint, resentment, rejection of each other. It is noted that the formation of the managerial capacity of technical college students is helpful to abandon the entrenched idea that psychology, pointing person distracts the head of its direct relationships, calling or engage in education, something moralizing, it ceases to be an exacting and strict manager. Psychology of management does not encourage the manager to play the role of a teacher, changed its management ideology. It comes from the fact that, in management theory and practice, there is a large "white spot" - an area of problems that are not only permits, but often do not even realize, causing nevertheless stress, general anxiety.

This white spot - the result of what is not considered two-layer structure of management. Its essence is simple: before the manager of any rank, if his authority is, at least one person, there are always two groups of tasks. The first - the tasks associated with the organization of the activities of its units, the interaction with other departments and senior management. The second problem - it the internal problems of units included in it people. It is a matter of labor morale or motivation activities, discipline, corporate culture, climate, relationships, health, personal and group of people, the credibility of the management and control.

Keywords: managerial capacity; psychological and pedagogical knowledge; university students; interpersonal communication; harmonization of interpersonal relations; behavioral regulation; communicative 
potential; the level of moral and ethical normativity; personally adaptive capacity; behavior and socialization strategy.

\section{References}

1. Kysse, A. Y., Demchenko, D. M., \& Anhelov, H. V. (2004). Natsyonalnыe osobennosty v sovremennom menedzhmente. Kyev-Odesa: SMYL.

2. Stremiadyn, V. V., Butsenko, Y. N., Polamarchuk, V. V., \& Anhelov, H. V. (2004). Chelovekovedcheskaia kompetentnost v sovremennom upravlenyy. Kyev- Odessa: SMYL.

3. Levchuk, V. V., Myshkovets, A. V., \& Kotlyk, S. V. (2009). Menedzhment: Ynnovatsyonno-stratehycheskye y psykholoho-эtycheskye aspektы. Odessa: Astroprynt.

4. Cherniak, H. A. (1997). Rol psykholohycheskykh znanyi v formyrovanyy upravlencheskykh navbkov u studentov tekhnycheskoho vuza. 57 Nauchn. Konf. Professorsko-prepodavatelskoho Sostava OHAPT : Tezysы Dokl, 21.

5. Cherniak, H. A., Anhelov, H. V., \& Zarychanskyi, A. P. (1999). Psykholohyia chelovecheskykh vzaymosviazei. Odessa:VMV.

6. Cherniak, H. A., Butsenko, Y. N., \& Kovalenko, L. F. (2008). Yskusstvo эffektyvnoho obshchenyia. Odessa: KP OHT.

7. Cherniak, H. A., Hordyenko, Y. A., \& Butsenko, Y. N. (2014). Poysk harmonyy v chelovecheskom vzaymoponymanyy. Kherson: Hryn D.S.

8. Ahelov, H. V., Semov, V. A., \& Chuhuenko, V. M. (1994). Psykholoho-pedahohycheskye osnovы upravlenyia proyzvodstvom. Kyev-Odessa: SMYL.

9. Teniuk, K. M., Stoiano, O. O., \& Demchenko, D. M. (2006). Samovyznachennia osobystosti studenta yak maibutnoho fakhivtsia. Kyiv-Odesa: SMIL.

10. Shuvalov, S. E., Romanenko, O. V., \& Anhelov, H. V. (1997). Sotsyoloho-psykholohycheskye rezervы menedzhmenta: Novыe podkhodы. Kyev-Odessa: SMYL.

Received 16 August 2016

Approved 30 August 2016

Available in Internet 30.09.2016 